

CHOICE

\title{
Measuring quality in the therapeutic relationship-Part 1: objective approaches
}

\author{
Trisha Greenhalgh, ${ }^{1}$ Iona Heath ${ }^{2}$
}

${ }^{1}$ Queen Mary University of London, London, UK

${ }^{2}$ Royal College of General Practitioners, London, UK

\section{Correspondence to}

Trisha Greenhalgh, Professor of Primary Health Care and Director, Healthcare Innovation and Policy Unit, Centre for Health Sciences, Barts and The London School of Medicine and Dentistry, Abernethy Building, 2 Newark Street, London E1 2AT, UK; p.greenhalgh@qmul.ac.uk

Accepted 18 July 2010

\begin{abstract}
Background The therapeutic relationship is complex. Any attempt to capture its quality in a score or metric must involve an element of reductionism. But policymakers increasingly ignore the unmeasured.

Aim To review the different concepts, theoretical models and empirical approaches which researchers have used to capture the relationship between practitioner and patient in terms of scales, categories and other objective metrics.

Method Drawing on the principles of meta-narrative systematic review (but without seeking an exhaustive inventory of every paper ever published), we considered different research traditions in terms of their respective philosophical assumptions, methodological strengths and limitations and empirical findings. We applied published quality criteria from each tradition to papers within that tradition.
\end{abstract}

Results Three main research approaches were oriented to producing objective data about the therapeutic relationship. These appeared to have emerged in different research traditions: patient satisfaction surveys (health services research), rate-your-relationship surveys (social psychology) and interaction analysis (cognitive psychology). Each emphasised a different dimension and produced a different perspective on quality.

Conclusions Objective metrics, when well designed, offer important insights into the therapeutic relationship, but its elusive essence remains imperfectly captured by the best of them.

\section{INTRODUCTION}

We live and work in a world of metrics. The unmeasurable makes us uneasy. The therapeutic relationship between a patient and his or her general practitioner, traditionally built over years while illnesses and life events came and went, has been depicted by numerous writers as rich, complex and essentially unmeasurable. ${ }^{1}$ But as an editor of the British Medical Journal recently asked, 'Is it wise to defend primary care solely by invoking its warm fuzzy heart, beating away in its black box, far from the close scrutiny of all but its adepts?'.

Others have sought to strip the therapeutic relationship of its mystery and sentimentality. Academics seeking to defend family medicine against the creeping menace of managed care in the USA claimed that it boiled down to six readily measurable Cs: choice, competence, communication, compassion, continuity (of care), and (no) conflict of interest. ${ }^{3}$

These positions represent the poles of a tension. The extent to which the therapeutic relationship eludes measurement is also the extent to which critics will denigrate it and policymakers will ignore it. On the other hand, any attempt to capture a complex, intersubjective phenomenon in terms of a simple score or category involves reductionism. In seeking to explore this tension, we ask three questions: First, how have researchers and scholars sought to measure or understand the therapeutic relationship? Second, what are the strengths and limitations of the various metrics and measures on offer? Third, what are the practical implications for quality improvement?

These questions are timely given the diversification in service models for general practice and primary care across the world. In the UK, for example, traditional general practice coexists uneasily with the emerging polyclinic model in an increasingly consumerist health economy. ${ }^{4}$ Canadian policymakers are seeking to replace scarce and expensive family physicians with nurse practitioners. ${ }^{5}$ China's goal of reforming health services by expanding the primary care sector has, to date, been achieved largely by appointing doctors and nurses with limited training or qualifications. ${ }^{6}$ Policymakers in the USA have introduced the notion of the "patient-centred medical home'. 'Those who seek to justify or challenge service innovations such as these will need an evidence base about what is valuable (and expendable) in the therapeutic relationship. This paper and its companion ${ }^{8}$ are based on a longer monograph (published by the London Kings Fund) which sets out in more detail the evidence for each aproach. $^{9}$

\section{METHOD}

The purpose of this review was not to offer a comprehensive inventory of every paper ever published on the therapeutic relationship but to produce a preliminary map of the different ways in which this relationship has been studied. We used an adaptation of meta-narrative review, based on Kuhn's notion of the scientific paradigm (a coherent body of work that shares a common set of concepts, theories, methods and instruments). ${ }^{10} 11$ This qualitative approach seeks to tease out the over-arching storylines of different research traditions by asking four key questions: how is the topic conceptualised in each separate tradition?; what are the key theory(ies)?; what are the preferred study designs and ways of knowing? and what are the main empirical findings? Meta-narrative review is pluralistic rather than normative (ie, it asks not "what is the best approach to researching this topic?' but 'what can we learn from the range of different approaches?'). It is particularly suited to exploring tensions and paradoxes between different research traditions and making sense of 'conflicting' findings. ${ }^{12}$ 
Having previously demonstrated that when reviewing complex and heterogeneous bodies of literature, asking experts in the field and 'snowballing' (pursuing references of references and electronic citation tracking) are more efficient and effective search methods than either database searching or hand searching, ${ }^{13}$ we built our data set iteratively, beginning with sources known to us. In appraising primary studies, we took our quality criteria from seminal sources in the tradition we were studying. For example, when considering questionnaire studies, we prioritised those which scored well on criteria such as reliability, validity and response rates. ${ }^{14}$

\section{MAIN FINDINGS}

\section{'Measuring' the therapeutic relationship: research approaches}

Exploratory searches suggested that approaches could be divided into two broad schools ('objective' and 'subjective'). In reality there is much overlap between them-for example, many 'objective' numerical scales are designed to capture and quantify respondents' subjective perceptions. The objective school defines research rigour in positivistic terms (accuracy, precision, reproducibility, inter-rater reliability and distancing from the data) while the subjective school defines rigour in interpretivist terms (strength of underpinning theory, coherence of concepts and explanations, reflexivity and immersion in the data).

The objective school (table 1) is oriented to producing verifiable and reproducible facts (such as scores, estimates of frequencies or lists of commonly occurring themes). It includes, but is probably not limited to,

1. Patient satisfaction surveys (whose roots are in health services research), which seek to determine the proportion of patients who score particular aspects of their healthcare experience positively.

2. Rate-your-relationship surveys (whose roots are in social psychology), which seek to quantify humanistic constructs like trust, interpersonal skills and responsiveness.

3. Interaction analysis (whose roots are in cognitive psychology), which considers the consultation in terms of the proportion of time spent on different types of talk.

The subjective school, oriented to generating interpretations rather than facts, includes psychodynamic analysis (eg, Balint method), narrative analysis, critical consultation analysis and socio-technical analysis. These are covered in another paper, which includes a discussion on the implications of our findings. ${ }^{8}$
Patient satisfaction surveys: the therapeutic relationship as a service transaction

Asking patients to rate their satisfaction with care is a popular approach to service evaluation. ${ }^{25-31}$ Three narrative systematic reviews considered what different satisfaction scales actually measure ${ }^{15}$; systematic biases associated with different expectations and willingness to complain in different demographic subgroups $^{32}$ and characteristics and correlates of 'satisfaction', of which a key determinant was found to be the doctor-patient relationship (variously measured). ${ }^{16}$ Such conclusions are, however, tautologous if the satisfaction instrument itself includes items on the therapeutic relationship.

Over 20 years ago, Smith and Armstrong demonstrated that patients' perspectives on quality in general practice (as identified in open-ended qualitative interviews) differed significantly from those in official metrics of quality recommended by the government and Department of Health. ${ }^{33}$ Patients valued humanistic and affective items (eg, 'staff are friendly and know me', 'doctor listens to me') more highly and items about organisation and governance (eg, 'surgery times are convenient', 'doctor goes on courses') less highly than the official rankings.

A recent qualitative systematic review identified 11 primary studies and found four key constructs-knowledge of the patient as a person, trust, loyalty (ie, commitment) and positive regard as perceived by the patient. ${ }^{34}$ Patients viewed quality of the relationship as dependent on personal (ie, whole person) care and continuity of care. Despite such findings, generic satisfaction instruments still tend to fight shy of overtly emotional questions such as 'do you think your doctor likes you?'. At best, they fail to represent these constructs in proportions that reflect patients' priorities.

Failure of satisfaction questionnaires to fully capture the essence of the therapeutic relationship is partly due to a tendency of health services researchers to conflate reliability of an instrument with its validity (ie, to assume that because responses show 'robust' psychometric properties such as reproducibility and internal consistency, the instrument is therefore measuring what needs to be measured). ${ }^{17}$ It may also be due to an unconscious and misguided tendency to devalue 'emotional' items as less rational or useful than 'dispassionate' ones $^{35}$ and to the fact that liking or being liked by a patient is not something that is amenable to incentivisation or performance management.

Table 1 Objective research approaches to the study of the therapeutic relationship (see companion paper for subjective approaches) ${ }^{8}$

\begin{tabular}{|c|c|c|c|c|}
\hline Approach & Discipline & General format of research question & Preferred study design & Quality defined in terms of \\
\hline \multirow[t]{2}{*}{$\begin{array}{l}\text { 1. Patient satisfaction } \\
\text { surveys }\end{array}$} & \multirow[t]{2}{*}{$\begin{array}{l}\text { Health services } \\
\text { research }\end{array}$} & $\begin{array}{l}\text { What do patients describe as important } \\
\text { in their healthcare experience? }\end{array}$ & Interviews, focus groups & \multirow{2}{*}{$\begin{array}{l}\text { Service transaction: What are the } \\
\text { 'customers' in the consultation looking } \\
\text { for; what proportion of them are receiving } \\
\text { it; and do health outcomes improve if they } \\
\text { get it? }{ }^{15-17} \text { Some instruments include } \\
\text { measures of patients' perceptions of } \\
\text { patient centredness or shared decision } \\
\text { making. }\end{array}$} \\
\hline & & $\begin{array}{l}\text { Of themes identified as 'important', what } \\
\text { is the contribution of each to satisfaction } \\
\text { and/or health outcome? }\end{array}$ & $\begin{array}{l}\text { Survey development with } \\
\text { main focus on closed-item } \\
\text { questionnaires oriented to } \\
\text { hypothesis testing }\end{array}$ & \\
\hline
\end{tabular}

2. Rate-your-relationship surveys Social and clinical psychology

3. Interaction analysis
Cognitive and social psychology
What do patients describe as important in the relationship they have with their practitioner, and what do these constructs predict?

What proportion of talk falls into what category (eg, 'care talk', 'cure talk', 'patient focused', 'doctor focused')?
As above - preliminary qualitative studies followed by survey development

Interaction analysis (coding of transcript into categories of talk and non-verbal exchange)
Quantifying the subjective experience: What level of trust, compassion and interpersonal warmth does the patient feel is present? ${ }^{18-21}$

Types of talk: What types of talk are occurring in the consultation and how much time is spent on each type ${ }^{21}$ To what extent is talk patient centred and/or to what extent is decision making shared? ${ }^{23} 24$ 
In some satisfaction instruments, the simple and overtly emotional constructs of trust, commitment and positive regard are replaced with two more clinically oriented composite constructs: patient centredness (thinking holistically, understanding the patient as a person, sharing power and responsibility, building a therapeutic alliance and understanding the doctor as a person ${ }^{36}$ ) and shared decision making ('define the decision, summarize the information available, prioritize information needs, elicit preferences and values, and foster meaningful communication among decision stakeholders' (page $418)^{37}$ ). Both constructs relate primarily to the practice of clinical care and not to the quality of the therapeutic relationship. Thus, while the evidence base on patient centredness and shared decision making is important in its own right, they were beyond the scope of this review.

\section{Rate-your-relationship surveys: quantifying the humanistic in the therapeutic relationship}

Surveys in which patients are asked emotional questions tend to be developed by social psychologists, for whom subjective and intersubjective dimensions of relationships (mother-infant, marital, therapeutic) are a key focus of enquiry. ${ }^{38}$ Anderson and Dedrick, for example, sought to measure trust-defined as 'a person's belief that the physician's words and actions are credible and can be relied upon' (page 1092). ${ }^{18}$ They began with a number of measures of generic interpersonal trust, critiqued and refined these into a preliminary scale, and then administered a draft survey to 160 patients attending chronic disease management clinics. Using statistical data reduction techniques, they refined the instrument into an 11-item scale with a Cronbach's $\alpha$ of 0.90 , consisting of statements like 'I trust my doctor to put my medical needs above all other considerations' and 'I sometimes worry that my doctor may not keep the information we discuss totally private'. Baseline scores on this scale were higher in patients who actively chose their physician; scores predicted continuity with a particular physician, self-reported adherence to medication and overall satisfaction with care. ${ }^{39} 40$

Hall et al measured liking ('all in all, I like this doctor a lot' and 'I think this doctor likes me a lot') on a 5-point scale in a sample of 261 patients attending diabetes clinic appointments. ${ }^{19}$ The 44 physicians in the study were also asked whether they liked their patient and whether they felt the patient liked them. Liking was usually mutual, directly correlated with satisfaction with care and inversely correlated with intention to change doctor. Patients rated behaviour of doctors whom they felt liked them more positively than behaviour of those they felt did not like them. These unsurprising findings illustrate that it is possible to measure liking and that patients feel better cared for when they feel liked by the doctor.

Greco et al used an exploratory qualitative phase followed by a pilot survey and item reduction to develop the 12-item Doctor's Interpersonal Skills Questionnaire (DISQ), which includes stems such as 'The warmth of the doctor's greeting to me was...' and 'The respect shown to me by this doctor was...' ${ }^{20}{ }^{41}$ Greco's team offered a service to family practitioners in which the DISO and other instruments are administered to patients and analysed independently (see http://www. cfep.co.uk).

Reis and colleagues developed the Patient Perception of Physician Responsiveness, defined as 'understanding of the patient's health care needs, acceptance of those needs as valid, and appropriate caring and support for those needs' ${ }^{21} 38$ Focus group participants were asked to talk about the relationship they had with their general practitioner; the authors also reviewed previous research on responsiveness in the social psychology literature. They administered a draft survey instrument to a broad sample of 800 adults in the USA, Canada and the UK and produced an 8-item scale by data reduction (box 1). Scores on this scale significantly correlated with subjective health-related problems over and above effects attributable to general satisfaction. To date, this simple but robust instrument has been little used in health services research, perhaps because it was published in a social psychology journal.

\section{Interaction analysis: the therapeutic relationship as a forum for information exchange and decision making}

The underlying assumption of interaction analysis is that talk in the clinical encounter can be broadly divided into (a) 'care' talk-affective or socio-emotional interaction, for example, building the therapeutic relationship and (b) 'cure' talkinstrumental or task-focused interaction oriented to preventing, diagnosing or treating disease. ${ }^{22}$ Interaction analysis involves sentence-by-sentence coding of verbatim transcripts of clinical encounters.

Patients tend to be more satisfied (and less likely to sue) when a higher proportion of the encounter relates to the socioemotional dimension. ${ }^{42}{ }^{43}$ Interaction analysis has been used to analyse consultation transcripts for patient centredness ${ }^{23} 44$ and shared decision making ${ }^{24} 45$ and to undertake cross-national comparisons of consulting behaviour. ${ }^{46}$ In short, different clinicians (and clinicians in different countries and cultural settings) spend a greater or lesser proportion of the consultation engaged in different types of talk.

Critiques of interaction analysis tools from within the objectivist school tend to question the psychometric properties of a particular coding instrument or suggest how it might be adapted or refined. ${ }^{47}$ Critics from the subjectivist school claim that this type of research is both under-theorised (studies are driven, they claim, by a naive and positivistic search for a list of factors that predict particular outcomes) and de-contextualised (the consultation is taken as a fixed unit of analysis without regard to the social or institutional context which shapes and constrains what is said and unsaid). ${ }^{48}$

\section{CONCLUSION}

While generic patient satisfaction questionnaires appear to be too broad in scope to capture the subtle and intimate nature of the therapeutic relationship, some less well-known studies by social psychologists have produced shorter and sharper instruments which focus directly on the patient's subjective perceptions of key elements of quality such as trust, interpersonal skills

\section{Box 1 Patient Perception of Physician Responsiveness}

Scale

Reproduced with permission from Reis et $a l^{21}$

1. Sometimes my doctor seems indifferent to my needs

2. My thoughts and feelings are important to my doctor

3. My doctor often really doesn't 'hear' what I am saying

4. Often, my doctor does not accept my feelings and concerns

5. My doctor dismisses my concerns too easily

6. My doctor is responsive to my needs and concerns

7. My doctor is concerned about me as a person

8. My doctor knows me as a person 


\section{Summary points}

1. Scholars argue about whether and how the therapeutic relationship between practitioner and patient should be measured.

2. In this paper we review some objective measures (oriented to producing 'facts') and consider their philosophical assumptions, methodological approaches and key findings.

3. While no single metric is capable of capturing all the dimensions and perspectives on the therapeutic relationship, different approaches illuminate this complex field in complementary ways.

and responsiveness. Interaction analysis appears to offer scope for opening the 'black box' of the therapeutic interaction and comparing such interactions systematically within and between settings, though critical academics have questioned its usefulness. A forthcoming companion article will consider how dimensions of the therapeutic relationship may be measured subjectively in ways which can complement and extend the objective approaches presented here and also considers the practical implications of the findings for quality improvement. ${ }^{8}$

Funding The King's Fund, 11-13 Cavendish Square, London, W1G OAN.

Competing interests None declared.

Contributors Both authors were involved in conceptualising the study, finding and reviewing primary research papers and writing the paper.

Provenance and peer review Not commissioned; externally peer reviewed.

\section{REFERENCES}

1. Heath I. The mystery of general practice. London: Nuffield Provincial Hospital Trust, 1997.

2. Delamothe T. A good 00Ffing whine. BMJ 2008;337:a2632.

3. Emanuel EJ, Dubler NN. Preserving the physician-patient relationship in the era of managed care. JAMA 1995;273:323-9.

4. Imison C, Naylor C, Maybin J. Under one roof: will polyclinics deliver integrated care? London: Kings Fund, 2008. http://www.kingsfund.org.uk/publications/ kings fund publications/under one roof.html.

5. Anon. IBM Business Consulting Services for the Ontario Ministry of Health and Long Term Care. Report on the Integration of Primary Health Care Nurse Practitioners into the Province of Ontario. Ottawa: Ontario Ministry of Health, 2004. http://www.health. gov.on.ca/english/public/pub/ministry_reports/nurseprac03/np_report.pdf Ref type: Report.

6. Yang J, Guo A, Wang $Y$, et al. Human resource staffing and service functions of community health services organizations in China. Ann Fam Med 2008;6:421-7.

7. American College of Physicians. The advanced medical home: a patient-centered, physician guided model for health care. New York: American College of Physicians Policy Monograph, 2006. http://www.acponline.org/hpp/adv_med.pdf.

8. Greenhalgh T, Heath I. Measuring quality in the therapeutic relationship. Part II: Subjective approaches. Quality and Safety in Health Care 2010;19:479-83.

9. Greenhalgh T, Heath I. Measuring quality in the therapeutic relationship. London: Kings Fund, 2010.

10. Greenhalgh T, Robert G, Macfarlane F, et al. Storylines of research in diffusion of innovation: a meta-narrative approach to systematic review. Soc Sci Med 2005; 61:417-30.

11. Kuhn TS. The structure of scientific revolutions. Chicago: University of Chicago Press, 1962.

12. Greenhalgh $\mathbf{T}$, Potts $\mathrm{H}$, Wong $\mathrm{G}$, et al. Tensions and paradoxes in electronic patient record research: a systematic literature review using the meta-narrative method. Milbank 0 2009:87:729-88.

13. Greenhalgh T, Peacock R. Effectiveness and efficiency of search methods in systematic reviews of complex evidence: audit of primary sources. BMJ 2005;331:1064-5.

14. Oppenheim AN. Questionnaire design, interviewing and attitude measurement. London and New York: Continuum, 1992

15. Chisolm A, Askham J. What do you think of your doctor? A review of questionnaires for gathering patients' feedback on their doctor. Oxford: Picker Institute Europe, 2006.
16. Sans-Corrales M, Pujol-Ribera E, Gene-Badia J, et al. Family medicine attributes related to satisfaction, health and costs. Fam Pract 2006;23:308-16.

17. Ramsay J, Campbell JL, Schroter S, et al. The General Practice Assessment Survey (GPAS): tests of data quality and measurement properties. Fam Pract 2000;17:372-9.

18. Anderson LA, Dedrick RF. Development of the trust in physician scale: a measure to assess interpersonal trust in patient-physician relationships. Psychol Rep 1990;67:1091-100

19. Hall JA, Horgan TG, Stein TS, et al. Liking in the physician-patient relationship. Patient Educ Couns 2002;48:69-77.

20. Greco M, Brownlea A, McGovern J, et al. Consumers as educators: implementation of patient feedback in general practice training. Health Commun 2000;12:173-93.

21. Reis HT, Clark MS, Pereira Gray DJ, et al. Measuring responsiveness in the therapeutic relationship: a patient perspective. Basic App/ Soc Psych 2008:30:339-48

22. Roter D, Larson S. The Roter interaction analysis system (RIAS): utility and flexibility for analysis of medical interactions. Patient Educ Couns 2002:46:243-51.

23. Henbest RJ, Stewart MA. Patient-centredness in the consultation. 1: a method for measurement. Fam Pract 1989;6:249-53.

24. Elwyn G, Edwards A, Wensing $M$, et al. Shared decision making: developing the OPTION scale for measuring patient involvement. Oual Saf Health Care 2003:12:93-9.

25. Marshall GN, Hays RD, Sherbourne CD, et al. The structure of patient satisfaction with outpatient medical care. Psychol Assess 1993;5:477-83.

26. Rubin HR, Gandek B, Rogers WH, et al. Patients' ratings of outpatient visits in different practice settings. Results from the Medical Outcomes Study. JAMA 1993;270:835-40.

27. Safran DG, Karp M, Coltin K, et al. Measuring patients' experiences with individual primary care physicians: results of a statewide demonstration project. J Gen Intern Med 2006;21:13-21.

28. Campbell J, Smith P, Nissen S, et al. The GP Patient Survey for use in primary care in the National Health Service in the UK-development and psychometric characteristics. BMC Fam Pract 2009:10:57.

29. Ipsos Mori for the Department of Health. Patient survey. London: Department of Health, 2009

30. Jayasinghe UW, Proudfoot J, Holton C, et al. Chronically ill Australians' satisfaction with accessibility and patient-centredness. Int J Qual Health Care 2008:20:105-14.

31. Grol R, Wensing M, Mainz J, et al. Patients in Europe evaluate general practice care: an international comparison. Br J Gen Pract 2000:50:882-7.

32. Sitzia J, Wood N. Patient satisfaction: a review of issues and concepts. Soc Sci Med 1997; 45:1829-43.

33. Smith $\mathbf{C H}$, Armstrong D. Comparison of criteria derived by government and patients for evaluating general practitioner services. BMJ 1989;299:494-6.

34. Ridd M, Shaw A, Lewis G, et al. The patient-doctor relationship: a synthesis of the qualitative literature on patients' perspectives. Br J Gen Pract 2009:59:e116-35.

35. Nussbaum M. Upheavals of thought: the intelligence of emotions. Cambridge: Cambridge University Press, 2001

36. Stewart M, Brown JB, Weston WW, et al. Patient centred medicine: transforming the clinical method. London: Sage, 1995

37. Dolan JG. Shared decision-making - transferring research into practice: the Analytic Hierarchy Process (AHP). Patient Educ Couns 2008;733:418-25.

38. Reis HT, Collins WA, Berscheid E. The relationship context of human behavior and development. Psychol Bull 2000;126:844-72.

39. Thom DH, Ribisl KM, Stewart AL, et al. Further validation and reliability testing of the Trust in Physician Scale. The Stanford Trust Study Physicians. Med Care 1999:37:510-17.

40. Mainous AG III, Baker R, Love MM, et al. Continuity of care and trust in one's physician: evidence from primary care in the United States and the United Kingdom. Fam Med 2001;33:22-7.

41. Greco M, Cavanagh M, Brownlea A, et al. Validation studies of the Doctors' Interpersonal Skills Questionnaire. Educ Gen Pract 1999:10:256-64.

42. Levinson W, Roter DL, Mullooly JP, et al. Physician-patient communication. The relationship with malpractice claims among primary care physicians and surgeons. JAMA 1997:277:553-9.

43. Paasche-Orlow $\mathbf{M}$, Roter D. The communication patterns of internal medicine and family practice physicians. J Am Board Fam Pract 2003;16:485-93.

44. Henbest RJ, Stewart M. Patient-centredness in the consultation. 2: does it really make a difference? Fam Pract 1990; 7:28-33.

45. Charles C, Gafni A, Whelan T. Shared decision-making in the medical encounter: what does it mean? (or it takes at least two to tango). Soc Sci Med 1997; 44:681-92

46. Deveugele $\mathbf{M}$, Derese $\mathrm{A}$, De BD, et al. Is the communicative behavior of GPs during the consultation related to the diagnosis? A cross-sectional study in six European countries. Patient Educ Couns 2004;54:283-9.

47. Sandvik M, Eide $\mathrm{H}$, Lind $\mathbf{M}$, et al. Analyzing medical dialogues: strength and weakness of Roter's interaction analysis system (RIAS). Patient Educ Couns 2002:46:235-41.

48. Scambler G, Britten N. System, lifeworld, and doctor-patient interaction. In Scambler G, ed. Habermas Critical Theory and Health. London: Routledge, 2001. 